\title{
Cerebrospinal Fluid Leakage and Cerebral Venous Sinus Thrombosis: A Case Report
}

Thana Theofanis, BS, 4 year Medical student

Thomas Jefferson University

Nohra El-Chalouhi, MD

Thomas Jefferson University

Stavropoula Tjoumakaris, MD

Thomas Jefferson University

Follow this and additional works at: https://jdc.jefferson.edu/jhnj

\section{Let us know how access to this document benefits you}

\section{Recommended Citation}

Theofanis, BS, 4 year Medical student, Thana; El-Chalouhi, MD, Nohra; and Tjoumakaris, MD, Stavropoula (2013) "Cerebrospinal Fluid Leakage and Cerebral Venous Sinus Thrombosis: A Case Report," JHN Journal: Vol. 8 : Iss. 1 , Article 2.

DOI: https://doi.org/10.29046/JHNJ.008.1.004

Available at: https://jdc.jefferson.edu/jhnj/vol8/iss1/2

This Article is brought to you for free and open access by the Jefferson Digital Commons. The Jefferson Digital Commons is a service of Thomas Jefferson University's Center for Teaching and Learning (CTL). The Commons is a showcase for Jefferson books and journals, peer-reviewed scholarly publications, unique historical collections from the University archives, and teaching tools. The Jefferson Digital Commons allows researchers and interested readers anywhere in the world to learn about and keep up to date with Jefferson scholarship. This article has been accepted for inclusion in JHN Journal by an authorized administrator of the Jefferson Digital Commons. For more information, please contact: JeffersonDigitalCommons@jefferson.edu. 


\section{Cerebrospinal Fluid Leakage and Cerebral Venous Sinus Thrombosis: A Case Report}

\author{
Thana Theofanis, BS ${ }^{1}$; Nohra Chalouhi, MD²; Stavropoula Tjoumakaris, MD² \\ ${ }^{1}$ Fourth year medical student, Jefferson Medical College, Philadelphia, PA \\ 2Department of Neurosurgery, Thomas Jefferson University and Jefferson Hospital for \\ Neuroscience, Philadelphia, Pennsylvania, USA
}

\section{INTRODUCTION}

Cerebrovascular venous thrombosis is an uncommon entity that may occur in the sinuses of the dura, the cortical veins, or the deep venous system. Common etiologies include states of hypercoagulability, such as oral contraceptives intake, malignancy, and trauma. Additional causes include inherent thrombophilic states, such as those caused by systemic lupus erythematosus, protein $\mathrm{C}$ or $\mathrm{S}$ deficiency, and antithrombin III deficiency. The pathogenesis of cerebral venous sinus thrombosis stems from the obstruction of venous outflow. Consequently, venous engorgement occurs, leading to decreased effective blood flow and white matter edema. Infarction or hemorrhage are not uncommon in the setting of venous thrombosis. Intracranial pressure also rises. The most common presenting symptom is headache.,

The impact of intracranial hypotension due to cerebrospinal fluid (CSF) leak on venous flow and thrombosis is not clear. ${ }^{1,-8,10,11}$ We present the case and treatment course of a patient who initially presented with an acute venous sinus thrombosis and in was later found to have a CSF leak and intracranial hypotension.

\section{CASE PRESENTATION}

The patient is a 42 -year-old woman without significant past medical history who presented to an outside hospital following a number of seizures that were witnessed by her husband. The patient was seen approximately 1 week prior to the seizures in an outside emergency room due to neck pain. She was diagnosed with a bulging disk at that point and treated with oxycodone/ acetominophen and muscle relaxants. She was transferred to Jefferson Hospital for Neuroscience where she was found to be agitated, tachycardic and hypertensive.
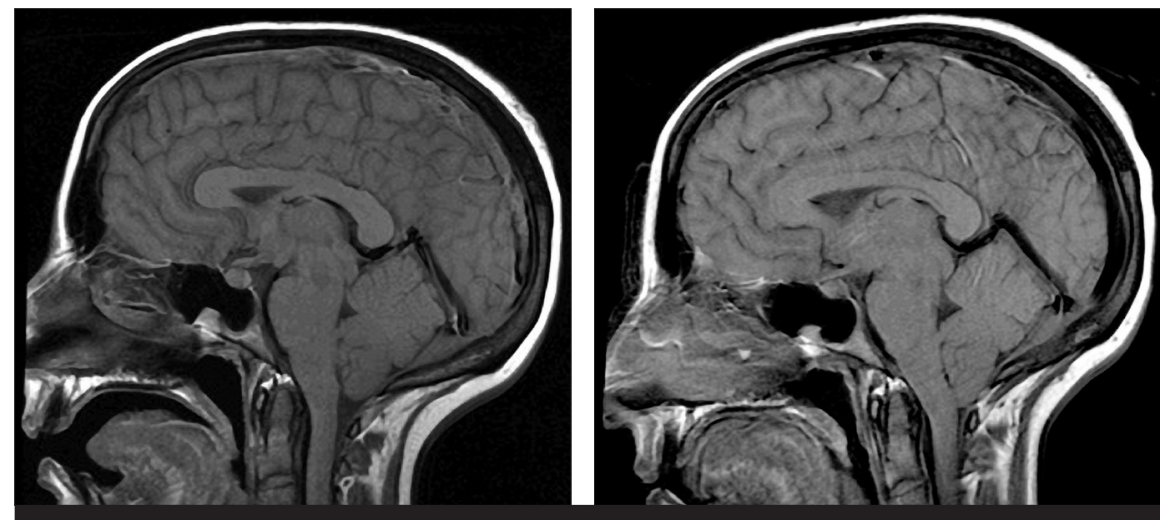

Figure 1

Head MRI of the patient revealed thrombus of the superior sagittal sinus, extending from vertex level to just above the confluence of the sinuses. There was additional thrombosis in the right-sided cortical veins with a possible short segment clot in the left transverse sinus
Head MRI revealed hyperintense T2 flair signal in the right frontal cortex likely due to venous congestion. There was thrombus in the superior sagittal sinus, extending from vertex level to just above the confluence of the sinuses. There was additional thrombosis in the right-sided cortical veins with a possible short segment clot in the left transverse sinus (see Figures 1 and 2). Ultrasonography of the legs was negative for deep venous thrombosis.

The patient was not taking oral contraceptives. She has a history of two uncomplicated vaginal births, no miscarriages, and her last menstrual period was 1 week prior to admission. The patient has no personal previous history of deep venous thrombosis, pulmonary embolism, bleeding, bruising or edema. The patient quit smoking approximately 1 week prior to admission.

A hypercoagulability work-up was performed. The patient was found to be heterozygous for the prothrombin 20210 gene variant. Also, the MTHFR gene was found to be heterozygous for C677T and negative for A1298C mutation. The patient was deemed to have a complex major thrombophilia secondary to these mutations.

No surgical intervention was undertaken during the initial hospitalization. The patient was placed on anticoagulation. On the 9th hospital day, the patient was deemed stable for discharge, and follow-up was arranged.

The patient presented one month after her initial hospitalization, with recurrent severe headache and blurred vision, without reported focal upper and lower extremity neurological symptoms or seizures. On imaging, the patient was found to have complete recanalization of the previously noted superior sagittal sinus thrombosis. Also of note, the patient did have findings consistent with intracranial hypotension, and extra-dural fluid along the dorsolateral aspect of the thecal sac extending from C7 through the lower thoracic spine, presumably epidural in location compatible with CSF leak. The cerebellar tonsils were also visualized to be protruding mildly below the foramen magnum (Figures 2 and 3). The patient and family refused any procedures such as blood patch and myelogram. Again, 


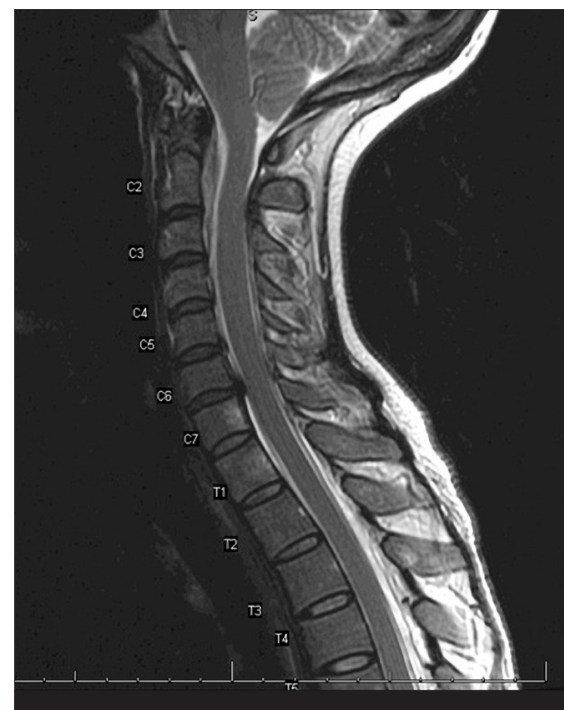

Figure 2

With further imaging on re-admission, the cerebellar tonsils were also visualized to be protruding mildly below the foramen magnum.

the patient underwent no surgical interventions during this second hospitalization. She was switched to Coumadin and deemed stable for discharge on the third hospital day.

\section{DISCUSSION}

This case report describes the rare relationship between cerebral venous sinus thrombosis and CSF leak. Upon work up to assess hypercoagulability, the patient was found to have two distinct mutations predisposing to venous sinus thrombosis. While spontaneous intracranial hypotension is rare, it was been found to be more common in females with a male:female ratio up to 1:4. Mean age of presentation is between the ages of 38 and 42 years old. 1, 5,7 Additionally, the site of CSF leakage in spontaneous intracranial hypotension has been found to occur predominantly the cervical and thoracic levels. CSF leakage resulting in spontaneous intracranial hypotension may be a misnomer, as it has been suggested that focal weak points in the dura that undergo a form of mechanical stress are more prone to be the sites of CSF leakage. ${ }^{7}$ As an example, the patient we present was seen in an ED for neck pain the week prior to presenting to our institution and was diagnosed with a bulging disk in the

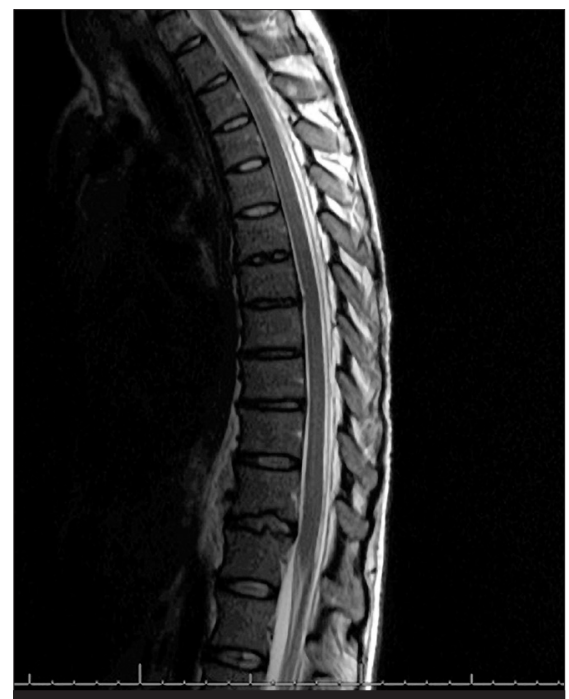

\section{Figure 3}

MRI revealed extra-dural fluid along the dorsolateral aspect of the thecal sac extending from $\mathrm{C} 7 \mathrm{thm}$.rough the lower thoracic spine, presumably epidural in location compatible with CSF leak.

\section{cervical spine.}

Yoon, et al., ${ }^{11}$ presented a case of an otherwise healthy 26 year-old male who presented with orthostatic headache and was subsequently found to have thrombosis in the sagittal sinus and CSF collection at the C1-2 level. The patient underwent an autologous blood patching procedure once, which resulted in prompt resolution of symptoms. They suggested that CSF leakage brings about increased intracranial blood volume and causes stasis of cerebral blood flow, particularly venous drainage, leading to thrombosis. ${ }^{11}$ It is likely that our patient had a subclinical CSF leak that remained undetectable on initial imaging. The combination of a low intracranial pressure with a thrombophilic state likely precipitated the cerebral venous sinus thrombosis in our case.

This mechanism was further elucidated by, Saviodaro, et al., ${ }^{6}$ who found areas of dural sinus sections to be approximately $70 \%$ larger in patients with spontaneous intracranial hypotension versus a normal pressure state. This physiologic compensation of venous dilatation accounts for the fall in CSF volume and pressure. However, this is not without consequence as the venous dilatation results in sluggish blood flow in the vessels of the intracranial venous system. Furthermore, CSF loss results in reduced absorption of CSF into the sinus. This causes increased blood viscosity, further contributing to the risk for thrombosis. ${ }^{7}$

\section{CONCLUSION}

We presented an uncomplicated case of acute venous sinus thrombosis and CSF leakage in a 42-year-old female. Currently, the relationship of these two entities is uncertain. Our case supports the hypothesis that CSF leakage and resulting intracranial hypotension may be a risk factor for cerebral venous sinus thrombosis.

\section{REFERENCES}

1. Berroir S, Grabli D, Heran F, Bakouche P, Bousser MG. Cerebral sinus venous thrombosis in two patients with spontaneous intracranial hypotension. Cerebrovasc Dis. 2004;17(1):9-12. doi: $10.1159 / 000073892$.

2. Bousser MG, Chiras J, Bories J, Castaigne P. Cerebral venous thrombosis-a review of 38 cases. Stroke. 1985;16(2):199-213.

3. Estanol B, Rodriguez A, Conte G, Aleman JM, Loyo $\mathrm{M}$, Pizzuto J. Intracranial venous thrombosis in young women. Stroke. 1979;10(6):680-684.

4. Rice CM, Renowden SA, Sandeman DR, Cottrell DA. Spontaneous intracranial hypotension and venous sinus thrombosis. Pract Neurol. 2013;13(2):120-124. doi: 10.1136/practneurol-2012-000257; 10.1136/ practneurol-2012-000257.

5. Richard S, Kremer S, Lacour JC, Vespignani H, Boyer P, Ducrocq X. Cerebral venous thrombosis caused by spontaneous intracranial hypotension: Two cases. Eur J Neurol. 2007;14(11):1296-1298. doi: 10.1111/j.1468-1331.2007.01947.x.

6. Savoiardo M, Armenise S, Spagnolo P, et al. Dural sinus thrombosis in spontaneous intracranial hypotension: Hypotheses on possible mechanisms. J Neurol. 2006;253(9):1197-1202. doi: 10.1007/ s00415-006-0194-z.

7. Schievink WI, Maya MM. Cerebral venous thrombosis in spontaneous intracranial hypotension. Headache. 2008;48(10):1511-1519. doi: 10.1111/j.1526-4610.2008.01251.x; 10.1111/j.15264610.2008.01251.x.

8. Sopelana D, Marcos A, Arroyo R, et al. May intracranial hypotension be a cause of venous sinus thrombosis? Eur Neurol. 2004;51(2):113-115. doi: $10.1159 / 000076791$.

9. Tian CL, Pu CQ. Dural enhancement detected by magnetic resonance imaging reflecting the underlying causes of cerebral venous sinus thrombosis. Chin Med J (Engl). 2012;125(8):1513-1516.

10. Qin X, Zhang X, Zhang Q. Cerebral venous sinus thrombosis caused by spontaneous intracranial hypotension. Neurology Asia. 2012:17(3): 227-230.

11. Yoon KW, Cho MK, Kim YJ, Lee SK. Sinus thrombosis in a patient with intracranial hypotension: A suggested hypothesis of venous stasis. a case report. Interv Neuroradiol. 2011;17(2):248-251. 